\title{
Morphological and ecophysiological adaptations of wild gilthead seabream Sparus aurata associated with tuna farms
}

\author{
Igor Talijančić, Tanja Šegvić-Bubić*, Iva Žužul, Tomislav Džoić, Jasna Maršić-Lučić, \\ Leon Grubišić
}

Institute of Oceanography and Fisheries, Šetalište Ivana Meštrovića 63, 21000 Split, Croatia

\begin{abstract}
Morphological and ecophysiological traits of wild, farmed and wild farm-associated gilthead seabream Sparus aurata were used to assess the degree of phenotypic adaptation of the species to their respective environments. Geometric morphometrics revealed clear body shape differentiation amongst the 3 types of populations, whereby significant differences were noted in head profile and the anterior-body region of the fish. Morphological resemblance was recorded among 2 gilthead seabream populations associated with tuna farms, indicating that they share the same phenotypic responsiveness pattern. Adaptation in reproductive investment strategy was observed in individuals from farm-associated origin, displaying the highest gonadosomatic index but lowest condition in comparison to their farmed and wild counterparts. Multinomial logistic regression revealed that sex change from male to female with increasing length was more pronounced in farm-associated fish than in farmed and and wild fish. These findings demonstrate a significant influence of the environmental factors inherent to tuna farms on the phenotypic characteristics of gilthead seabream, providing a basis for further research on the ecological effects of tuna farms on local marine populations.
\end{abstract}

KEY WORDS: Gilthead seabream - Aquaculture impact · Farm-associated fish $\cdot$ Phenotypic plasticity $\cdot$ Morphology $\cdot$ Fitness

\section{INTRODUCTION}

The deterministic role of the environment plays a crucial part in the evolution of phenotypes, especially when considering that many individual characteristics are phenotypically plastic due to the ability of a single genotype to produce multiple phenotypes as a function of environmental conditions (Swain \& Foote 1999, Sultan \& Stearns 2005). Fish body shape is the product of genetic makeup and ontogenetic allometry, where differential phenotypic characteristics may be attributed to environmental influences rather than to genetic differentiation (Swain \& Foote 1999, Cadrin 2005). Morphological and physiological traits

\footnotetext{
*Corresponding author: tanja.segvic@izor.hr
}

are often assumed to reflect adaptation to environmental factors such as temperature (Koumoundouros et al. 2009, Loizides et al. 2014, Nikolioudakis et al. 2014), type of food (Dempster et al. 2011, Abaad et al. 2016) and time the organisms have spent in the given environment (Fleming et al. 1994, Rogdakis et al. 2011, Lorenzen et al. 2012, Wringe et al. 2015). The existence of a relationship between phenotypic variation among fish populations and their functional ecology allows researchers to assess the degree to which a population can modify its fitness in relation to its feeding behaviour and habitat use (Leisler \& Winkler 1985, West-Eberhard 1989, Costa \& Cataudella 2007).

(C) The authors 2019. Open Access under Creative Commons by Attribution Licence. Use, distribution and reproduction are unrestricted. Authors and original publication must be credited. 
The attraction effect of fish farms on wild fish populations (Dempster et al. 2005, Sanchez-Jerez et al. 2011, Šegvić-Bubić et al. 2011c, Stagličić et al. 2017) and the ecological and genetic impacts of escapees on wild counterparts (Rogdakis et al. 2011, ŠegvićBubić et al. 2011a, 2014, 2017, Arechavala-Lopez et al. 2013, Toledo-Guedes et al. 2014a,b) have been widely studied and provide the basis for recommendations to manage escape scenarios (ArechavalaLopez et al. 2013, 2014, 2018a,b, Dempster et al. 2018). External characteristics (e.g. colour patterns, fin erosion, scale features), coupled with morphometry (e.g. body and otolith shape, condition index), have proven to be highly accurate and easily manageable tools for discriminating the origins of gilthead seabream Sparus aurata due to their simplicity in deployment, which does not require broader expert knowledge or specialisation (ArechavalaLopez et al. 2013). However, morphological resemblance between populations can also be viewed as a proxy measure for similarities in habitat use (Olsson et al. 2007), suggesting that morphometry analysis is primarily sensitive in the detection of recent escape events before the convergence from the farmed to the wild morphotype 'sets' in the natural habitat (Šegvić-Bubić et al. 2014).

In conjunction with selective breeding programmes targeting desirable production traits (e.g. high growth rate, disease resistance), farming conditions aim to further foster growth rates in cultured fish through a constant food supply at high stocking densities. Different foraging behaviour of farmed gilthead seabream in comparison to their wild counterparts (Arabaci et al. 2010) has likely enhanced the pattern of divergence from the spindle/elongated shape to the more inherent bulkier/stocky body form in cultured fish.

Similarities in terms of diet preferences of wild and farmed fish can be seen between fish farm-impacted areas and farm facilities (Arechavala et al. 2012b, 2014, Abaad et al. 2016). Sea cages have aggregative effects on local fish populations, impacting their presence, abundance, residence times and diet composition (Sanchez-Jerez et al. 2011). In the case of seabream and European seabass Dicentrarchus labrax farming, introduction of pellets into the marine environment influences the biological condition and metabolic status of surrounding fish due to the year-round feed availability of this food source and the different nutrient content in relation to natural food resources (Tuya et al. 2006, Fernandez-Jover et al. 2008, 2011, Sanchez-Jerez et al. 2011).

Research on the ecological impacts of inshore and coastal finfish farms on the surrounding environment and biota is well documented, whereas there is limited information for semi-offshore locations where tuna are farmed. Differences in the surrounding wild fish assemblages around tuna and other finfish farms are mainly associated with the type of feed used and the environmental conditions at the locations of these facilities (Šegvić-Bubić et al. 2011c, Stagličić et al. 2017). Tuna farms require excessive quantities of feed in the form of fresh or defrosted baitfish, which greatly differ from pellets that are used at seabream and seabass farms, in terms of proximate composition, leachability, dimensions and settling velocities (Vita et al. 2004, Aguado-Giménez \& García-García 2005, Vassallo et al. 2006, Fernandes et al. 2007, Šegvić-Bubić et al. 2011c), forming high-quality habitats that enhance the fitness of coastal fish assemblages (Stagličić et al. 2017).

The Sparidae are one of the most abundant families found year-round in wild fish assemblages aggregating around tuna sea cages in Croatia (Šegvić-Bubić et al. 2011c, Stagličić et al. 2017). They are also exploited and farmed commercially for human consumption, and fished recreationally (Basurco et al. 2011). We selected the gilthead seabream as a representative species for the assessment of morphological and physiological adaptations to conditions in the wild, as a farmed species and in wild aggregations around tuna farms. The aim of this study was to: (1) differentiate body shapes according to origin, (2) evaluate the potential for identifying farmed escaped gilthead seabream in the wild using geometric morphometric tools and (3) improve our understanding of the effects of tuna farms on the fitness of wild gilthead seabream residing around these farms by assessing condition, gonadosomatic index and sex change during the spawning period.

\section{MATERIALS AND METHODS}

\subsection{Fish sampling}

A total of 1438 gilthead seabream were acquired from 2 wild tuna farm-associated, 5 farmed and 7 wild (but not farm-associated) populations in the eastern Adriatic Sea. Sampling was performed during the spawning season of the species from October to December in 2 years: 2015 and 2016 (Table 1, Fig. 1). The origin of farmed fish varied according to the fingerling supplier. Farmed gilthead seabream comprised individuals of French, Italian and Croatian origin. Farm-impacted areas were represented by 2 tuna farms located off the eastern coast of the Adri- 
Table 1. Morphological data of gilthead seabream collected during 2015 and 2016 in the eastern Adriatic Sea. Conv.: conventional, $\mathrm{N}$ : total number of individuals sampled in both years, TL: total length, Wt: total weight

\begin{tabular}{|c|c|c|c|c|c|c|c|c|c|}
\hline \multirow[t]{2}{*}{ Sampling location } & \multirow{2}{*}{$\begin{array}{l}\text { Site } \\
\text { abbr. }\end{array}$} & \multirow[t]{2}{*}{ Origin } & \multirow[t]{2}{*}{$\mathrm{N}$} & \multirow[t]{2}{*}{2015} & \multirow[t]{2}{*}{2016} & \multicolumn{2}{|c|}{$\longrightarrow \mathrm{TL}(\mathrm{cm}) \longrightarrow$} & \multicolumn{2}{|c|}{$-W t(g)-$} \\
\hline & & & & & & Range & Mean \pm SD & Range & Mean \pm SD \\
\hline Brač tuna farm & $\mathrm{AB}$ & Farm-associated & 188 & 77 & 111 & $16.9-47.9$ & $27 \pm 3.6$ & $80.1-1250$ & $293.6 \pm 128.6$ \\
\hline Kali tuna farm & $\mathrm{AK}$ & Farm-associated & 237 & 127 & 110 & $21.9-32.1$ & $25.7 \pm 1.8$ & $141-451$ & $230.2 \pm 54.5$ \\
\hline French offspring conv. & FR & Farmed & 150 & 75 & 75 & $21.5-34.2$ & $29 \pm 2.9$ & $148-594$ & $399.7 \pm 101.8$ \\
\hline Italian offspring conv. & FI & Farmed & 98 & 48 & 50 & $19.9-28$ & $24.5 \pm 1.9$ & $114-495$ & $230 \pm 63.7$ \\
\hline Italian offspring organic & FT & Farmed & 97 & 47 & 50 & $25.5-30.3$ & $28 \pm 0.9$ & $230.5-440$ & $351.5 \pm 39.3$ \\
\hline Croatian offspring conv. & $\mathrm{FC}$ & Farmed & 99 & 49 & 50 & $23.8-35.3$ & $28.5 \pm 2.4$ & $212-768$ & $368.4 \pm 107.6$ \\
\hline Croatian offspring organic & $\mathrm{FH}$ & Farmed & 59 & 29 & 30 & $26.4-33.2$ & $28.5 \pm 1.9$ & $303-701$ & $401 \pm 107$ \\
\hline Dubrovnik & WD & Wild & 57 & 57 & - & $24.3-50.9$ & $31.7 \pm 6$ & $227-1502$ & $477.9 \pm 279.8$ \\
\hline Istria & WI & Wild & 99 & 40 & 59 & $22.8-29$ & $26 \pm 1.5$ & $98.9-374$ & $268.2 \pm 54.3$ \\
\hline Novigrad Sea & WN & Wild & 90 & 57 & 33 & $21.6-26.4$ & $23.78 \pm 1.2$ & $147.6-258.1$ & $196.7 \pm 27.3$ \\
\hline Trogir & WG & Wild & 31 & - & 31 & $22.9-28.5$ & $26.3 \pm 1.4$ & 179-291 & $236.3 \pm 30.6$ \\
\hline Unije & WU & Wild & 51 & 51 & - & $23.9-29.8$ & $26.7 \pm 1.5$ & $191.3-416.9$ & $293.7 \pm 53.5$ \\
\hline Velebit Channel & WV & Wild & 97 & 60 & 37 & $22.6-30.1$ & $25.9 \pm 1.5$ & $148-432.8$ & $258.7 \pm 52.3$ \\
\hline Tar Bay & WT & Wild & 85 & 41 & 44 & $12.2-24.7$ & $19.7 \pm 2.6$ & 23-195 & $105.8 \pm 36.4$ \\
\hline
\end{tabular}

atic Sea, 1 off the southwest coast of the island of Brač (AB) and the other off the southeast coast of the island of Ugljan (AK). Both facilities are located in 2 major aquaculture zones where tuna cage infrastructures are deployed $2 \mathrm{~km}$ from other finfish installations. Tuna-farming activities have been taking place for over $10 \mathrm{yr}$ at semi-offshore locations settled $300 \mathrm{~m}$ away from the coastline at a depth of 50 to $60 \mathrm{~m}$. The annual farming capacity of the Brač farm is around $900 \mathrm{t}$, with a sea concession surface of approximately $70100 \mathrm{~m}^{2}$, while the aquaculture concession of the Ugljan farm covers $420600 \mathrm{~m}^{2}$ of sea surface and has an annual production capacity of $1400 \mathrm{t}$. The 7 wild fish sampling locations were selected as unimpacted areas without farming activities, where the minimum distance between sampling localities and fish-farming activities was at least $50 \mathrm{~km}$, and were distributed along the entire eastern Adriatic coast, from the Istrian Peninsula in the north to Dubrovnik in the south.

Farm-associated specimens were sampled by fish hooks in the vicinity of sea cages ( 10 $\mathrm{m}$ max from the sea cage) at a depth of 40-60 m, while wild specimens were primarily obtained from fishing landings of local seiners at each location. Farmed population origin information was obtained from the farmers through the traceability of juvenile production or purchase documents.

\subsection{Geometric morphometrics}

For the purpose of this study, a digital camera carrier was constructed to facilitate the acquisition of body shape characteristics and to reduce the effect of parallax on geometric morphometric data (Mullin \& Taylor 2002). All procedures regarding photo sessions and the digitalisation process were performed by the same person to minimise measurement error that can result from different positioning of the specimen under the camera and variation caused by multiple operators.

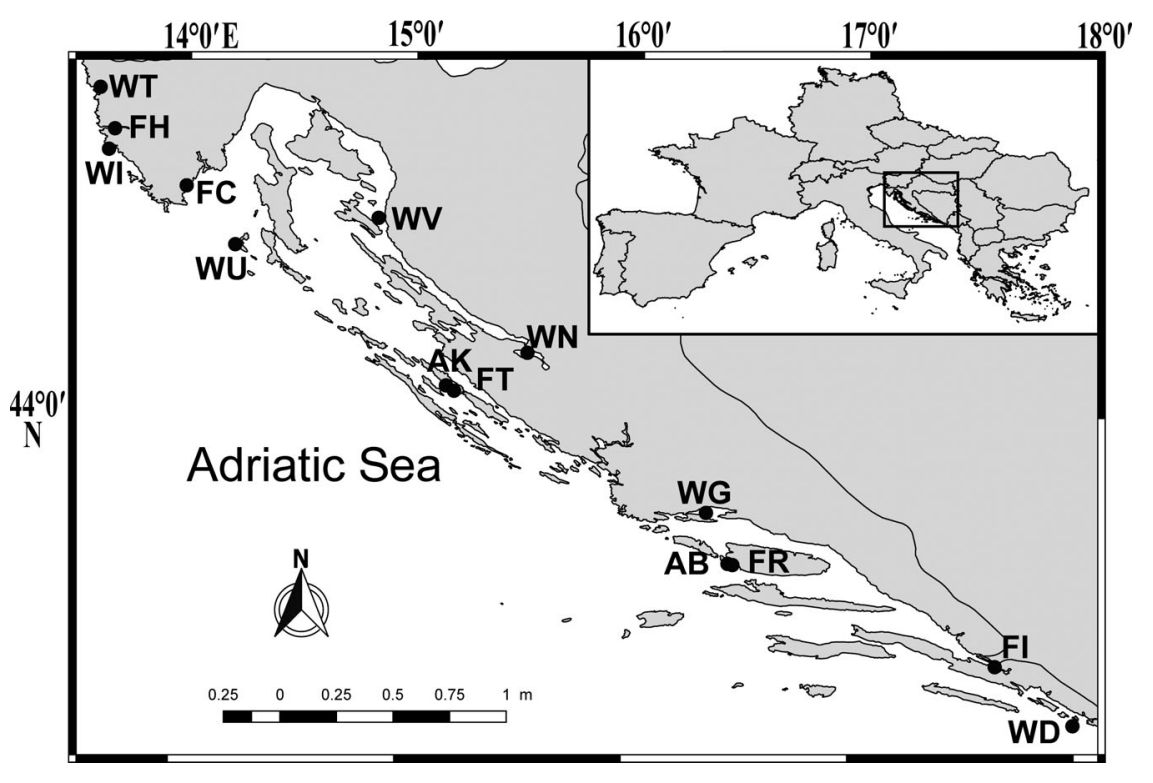

Fig. 1. Adriatic Sea, showing sampling locations of farm-associated, farmed and wild Sparus aurata populations along the eastern Adriatic coast. See Table 1 for abbreviations 
Total length (cm) and weight $(\mathrm{g})$ were recorded for each individual. Fish were placed at the centre of an expanded polystyrene block with $1 \mathrm{~cm}$ ruler gradation to ensure correct calibration in the following image data acquisition process. Body posture and fins were teased into a neutral position with needles of appropriate length to minimise the arching effect on the fish body. Lateral pictures of the left side of each sampled gilthead seabream were taken using a Canon EOS 600D digital camera.

Quantification and visualisation of gilthead seabream body shapes were attained by applying geometric morphometric methods (Bookstein 1991). A total of 18 anatomical landmarks were selected (Fig. S1 in the Supplement at www.int-res.com/ articles/suppl/q011p097_supp.pdf) to obtain the overall body shape of each specimen using TpsDig 2 software (Rohlf 2001). In the MorphoJ software package (Klingenberg 2011), generalized Procrustes superimposition was performed to separate size and shape components of form variation. Shape coordinates were computed from raw coordinates of configurations by scaling them to unit centroid size and by minimising differences in translation and rotation of all specimens until the sum of the squared distances (Procrustes distances) between the corresponding landmarks was minimised.

The amount of shape variation related to size was quantified by applying multivariate regression of the Procrustes coordinates on centroid size, with a permutation test using 10000 runs in the MorphoJ software package. However, before the residuals of the regression could be used as 'size-free' variables in subsequent statistical shape analyses, a homogeneity of slopes test was performed in order to validate if a fit of a common regression line to all groups or to a common model using a pooled within-group covariance procedure could be obtained. By using the geomorph R package (Adams \& Otarola-Castillo 2013), Procrustes ANOVA/regression for allometry with 1000 permutation runs was performed on the Procrustes-aligned coordinates obtained from MorphoJ.

Size composition differed among fish origins, and a small yet significant $(4.2 \%, \mathrm{p}<0.0001)$ amount of shape variation was related to size. In addition, the homogeneity of slopes test recorded significant group allometries ( $\mathrm{p}<0.001)$, implying that a fit to a common regression line or to a common model for size correction of shape variables is not justified (Fig. S2). As one of the objectives of the study was to investigate how much body shapes differ between origins in the second and third age class (see means of population total lengths in Table 1), the effect of size $(4.2 \%)$ on shape variables was not removed and as such was considered in further statistical analyses.

Canonical variate analysis (CVA) was performed in the MorphoJ software package to determine which shape features best distinguished the different origins of gilthead seabream. Pairwise comparisons of mean shapes from different origin populations were based on Procrustes distances, and a permutation test with 10000 runs was performed to test the null hypothesis of no difference between samples. A Bonferroni correction for multiple tests for an experiment-wise error rate of 0.01 was used (Rice 1989). Moreover, Procrustes shape coordinates were also used to plot specimen ordination and to predict group affiliation using PAST 3.0 software (Hammer et al. 2001), applying the jack-knife cross-validation procedure.

\subsection{Length-weight relationship, biometric indices and sex categorisation}

Statistical analyses of the length-weight relationship (LWR), relative condition $(K n)$, gonadosomatic index (GSI) and multinomial logistic regression (MLR) were computed using $\mathrm{R}$ ( $\mathrm{R}$ Core Team 2013) on a reduced dataset $(n=1024)$ including only individuals of 22 to $31 \mathrm{~cm}$ total length. The confined size range enabled exclusion of immature fish from the analysis considering that length-weight data are sensitive to slight differences in body shapes and growth stanzas. This is most evident in the early life stages of many fish species which have not yet obtained an adult body shape (Le Cren 1951, Safran 1992) and in older specimens whose body forms are often distorted due to unusually high proportions of fat (Froese 2006).

LWR and Kn represents 2 different, but interconnected, parameters in the analysis of length-weight data. LWR can provide morphological information due to the possible interpretation of the exponent $b$, whose deviation from 3.0 can suggest the direction and rate of change of form or condition, whereas Kn can be viewed as a short-term indicator of fish wellbeing since it is primarily influenced by food availability, body shape, gonad growth, sexual maturity and reproductive cycles (Hile 1936, Le Cren 1951, Policansky 1983, Pope \& Kruse 2007). Analysis of LWR was based on the least-squares regression model $\left(y_{i}=\beta_{0}+\beta_{1} x_{i}+\varepsilon\right)$, using the following equation:

$$
\log _{10}(\mathrm{TW})=a+b \times\left(\log _{10} \mathrm{TL}\right)
$$

where total weight (TW) corresponds to the dependent $y_{i}$ and total length (TL) to the independent $x_{i}$ vari- 
able, $a\left(\beta_{0}\right)$ is the $y$-intercept, and $b\left(\beta_{1}\right)$ is the slope of the line. Regression of $\log _{10} \mathrm{TL} \times \log _{10}$ TW was performed to assess if different incremental weight gain and condition status existed between the observed origins of gilthead seabream in the eastern Adriatic Sea.

ANCOVA was used to compare regression lines of sampled length-weight data to test differences in slopes and intercepts. Building on the least-squares regression of $\log _{10} \mathrm{TL} \times \log _{10} \mathrm{TW}$, the ANCOVA model is represented by the following equation:

$$
\mathrm{TW}=\beta_{0}+\beta_{1} \mathrm{TL}+\beta_{2} \text { Origin }+\beta_{3} \mathrm{TL} \text { :Origin }
$$

where TW is the response variable, $\beta_{0}$ is the $y$-intercept, TL is the covariate independent variable, Origin is the categorical independent variable that represents the effect on weight, and $\beta_{3}$ TL:Origin is the interaction term. Tukey's post hoc test was applied to identify differences among origins in LWR, since differences in slopes can reveal changes in growth rate if the interaction term is significantly different from 0 . In the case of no significant interaction, the regression lines are displayed in parallel fashion, indicating that the weight gain rate between observed origins is similar as individuals increase in length. Moreover, we wanted to investigate if there was a significant elevation difference between parallel regression lines through the analysis of intercepts, where discrepancies may indicate a better condition of one population over another at a given length (Pope \& Kruse 2007). This was tested by replacing the interaction term with the following equation:

$$
\mathrm{TW}=\beta_{0}+\beta_{1} \mathrm{TL}+\beta_{2} \text { Origin }
$$

The least-squares regression coefficients estimated from the LWR were also used to compare the condition status between farm-associated, farmed and wild specimens through $K \mathrm{n}$, since it compensates changes in body form or condition with increasing length (Le Cren 1951). Kn was calculated as:

$$
K \mathrm{n}=\frac{T W}{W_{e}^{\prime}}
$$

where $W_{e}^{\prime}$ is the predicted length-specific weight $(a \times$ $\mathrm{TL}^{b}$ ) based on $\log _{10}$-transformed data. Specimens with higher or lower values of $\mathrm{Kn}$ are considered to be in better or worse condition, depending on their distance from the benchmark of 1 .

Gonad weight per fish (GW) was measured to the nearest $0.01 \mathrm{~g}$. Fish sex was determined macroscopically, and individuals were categorised as male, female or in the intersex phase (in cases when male and female parts of the gonads occurred together).
Fish sampling during the spawning season allowed reliable sex categorisation of adults. The GSI was calculated on eviscerated fish (EW) as:

$$
\mathrm{GSI}=\frac{\mathrm{GW}}{\mathrm{EW}} \times 100
$$

The non-parametric Mann-Whitney $U$-test was used to test GSI variability of fish sampled in 2 consecutive years (2015 and 2016). Statistical differences of $\mathrm{Kn}$ and GSI among the observed origins were tested by ANOVA $(p<0.05)$ and Tukey's post hoc test. Assessment of the homogeneity of variances was performed through Levene's test.

Temperature has an effect on the speed of various reproductive processes (e.g. gonadal development, maturation, sex change etc.) and acts as a minimum/maximum threshold for fish spawning (Moretti et al. 1999). In order to explore sea surface temperature (SST) between the same period in different sampling years (2015 and 2016, October to December interval only), monthly averages and standard deviation of SST were calculated from daily averages of satellite SST. Daily averages of satellite SST interpolated for the Mediterranean Sea through an optimal interpolation algorithm were downloaded from the Copernicus Marine Environment Monitoring Service database (marine.copernicus.eu). The Consiglio Nazionale delle Richerce reprocessed the Pathfinder V5.2 (PFV52) AVHRR data over the period November 1981 to December 2017 to provide daily gap-free maps (L4) at the original PFV52 resolution at $0.0417^{\circ} \times$ $0.0417^{\circ}$ (Pisano et al. 2016).

MLR was applied as a quantitative method for analysing categorical sex data and used for the likelihood evaluation of trends of sex change in protandrous hermaphrodite gilthead seabream for the observed length-weight interval. The application of MLR was carried out to predict the probabilities of the outcome of a categorical dependent sex variable, in which log odds of the outcomes were modelled as a linear combination of the continuous 'Total length' and the categorical 'Origin' predictor variable. The regression model for the multinomial sex response was developed by selecting the male sex category as the baseline for forming the odds of the remaining sex categories. Furthermore, the base level for the categorical 'Origin' variable was set to 'Wild', since our prediction of sex change in gilthead seabream (male $\rightarrow$ intersex phase $\rightarrow$ female) was based on the assumption that this occurs differently in farmassociated and farmed stocks in comparison to wild ones. In the present study, the MLR was expressed as: 
$\log \frac{\operatorname{Prob}\left(y_{i}=j\right)}{\operatorname{Prob}\left(y_{i}=\text { male sex }\right)}=\begin{aligned} & \left.\beta_{0}+\beta_{1}(\mathrm{TL})+\beta_{2} \text { (Origin }\right)+ \\ & \beta_{3}(\text { TL:Origin })\end{aligned}$

where $y_{i}$ is the response variable (sex), $\beta_{0}$ is the constant, $\beta_{1,2,3}$ are regression parameters that quantify the relationships between the predictor and response variables, and $j$ is the observed sex category (intersex phase, female). Wald statistics were also computed to test if the regression coefficients of the predictors significantly contributed to the prediction of the response sex category outcome.

\section{RESULTS}

\subsection{Geometric morphometrics}

The sampled origins significantly differed in their average body shapes ( $p<0.0001)$ for all 3 pairwise origin comparisons. Procrustes distances of farmassociated (FA) vs. farmed origin (FO) and FO vs. wild origin (WO) showed similar values (0.016 vs. 0.018 ) in contrast to the very weak distance observed for FA vs. WO fish (0.0066). The main body shape differences from the overall mean configuration were evident in the head and trunk region, dorsoventral body axes and caudal peduncle length (Fig. 2). FO fish were characterised by a stocky body form due to an extension of the abdomen region (Landmarks 10, 11, 12; see Fig. S1 for Landmark definitions) and contraction of the trunk (Landmarks 3, 4, $10,11)$ and head area (Landmarks 1, 2, 3, 12, 13, 14). WO fish displayed a distinguishable spindle-like elongated body shape with the mouth positioned subterminally on a large head profile (extension of Landmarks $2,3,12,13,14)$. Body shape features of FA gilthead seabream appeared more similar to WO individuals, with head profiles slightly larger than in FO ones, but with a significantly bulkier body shape than in WO specimens.

The 2 canonical variates (eigenvalues 4.62 and 0.39 ) explained 92.14 and $7.86 \%$ of the total variance between landmark configurations in the overall sample. The jack-knifed discriminant analysis correctly classified $84.01 \%$ individuals to their origin (Table 2). The CVA ordination plot illustrated a pronounced discrimination in morphological features when comparing FO to FA and FO to WO (Fig. 3). The FO specimens had the highest correct classification rate $(97.6 \%)$, demonstrating clear segregation from WO individuals, with minor overlap with FA specimens on the ordination plot (Table 2, Fig. 3). Misclassifications of FO fish were low, with $2 \%$ assigned to FA

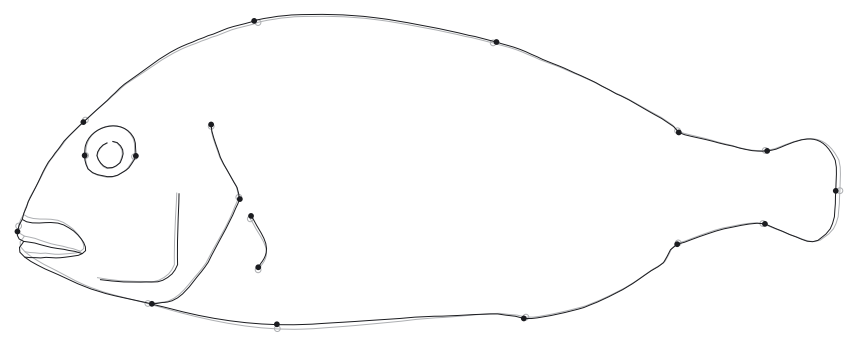

A) Farm-associated

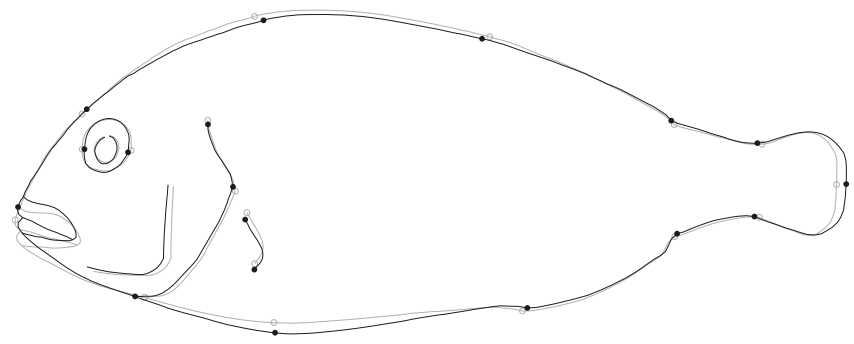

B) Farmed

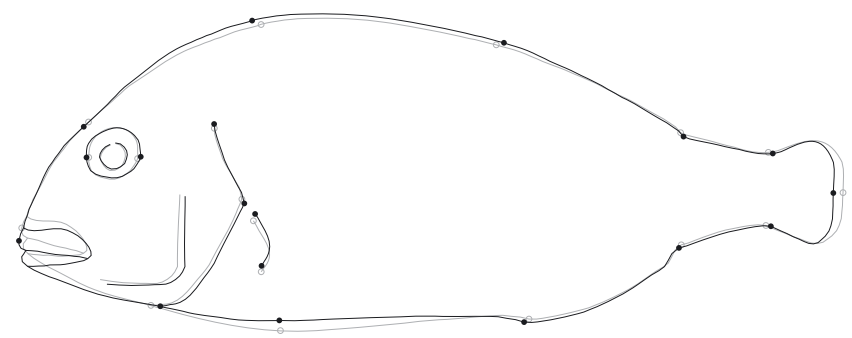

\section{C) Wild}

Fig. 2. Warped outline drawings of mean shapes for gilthead seabream from different origins. The light grey outline represents the transformation from the overall mean shape, while the black outline represents the mean shape of each origin. Analysis of Procrustes distances showed that all 3 pairwise origin comparisons were significantly different $(\mathrm{p}<$ 0.0001). The shape differences were exaggerated 2 -fold for better visualisation. The landmarks are defined in Fig. S1 in the Supplement

Table 2. Jack-knife classification score results (in counts and $\%$ ) for the canonical variate analysis of the 3 origins of gilthead seabream from the eastern Adriatic Sea (FA: farm-associated, FO: farm origin, WO: wild origin). Overall, the jack-knifed discriminant analysis correctly classified $84.01 \%$ individuals to their origin

\begin{tabular}{|llcccc|}
\hline & & FA & FO & WO & Total \\
\hline \multirow{6}{*}{ Count } & FA & 329 & 11 & 85 & 425 \\
& FO & 10 & 491 & 2 & 503 \\
& WO & 120 & 2 & 388 & 510 \\
& Total & 504 & 475 & 459 & 1438 \\
$\%$ & FA & 77.40 & 2.60 & 20.00 & 100 \\
& FO & 2.00 & 97.60 & 0.40 & 100 \\
& WO & 23.52 & 0.40 & 76.08 & 100 \\
& Total & 35.05 & 33.03 & 31.92 & 100 \\
\hline
\end{tabular}




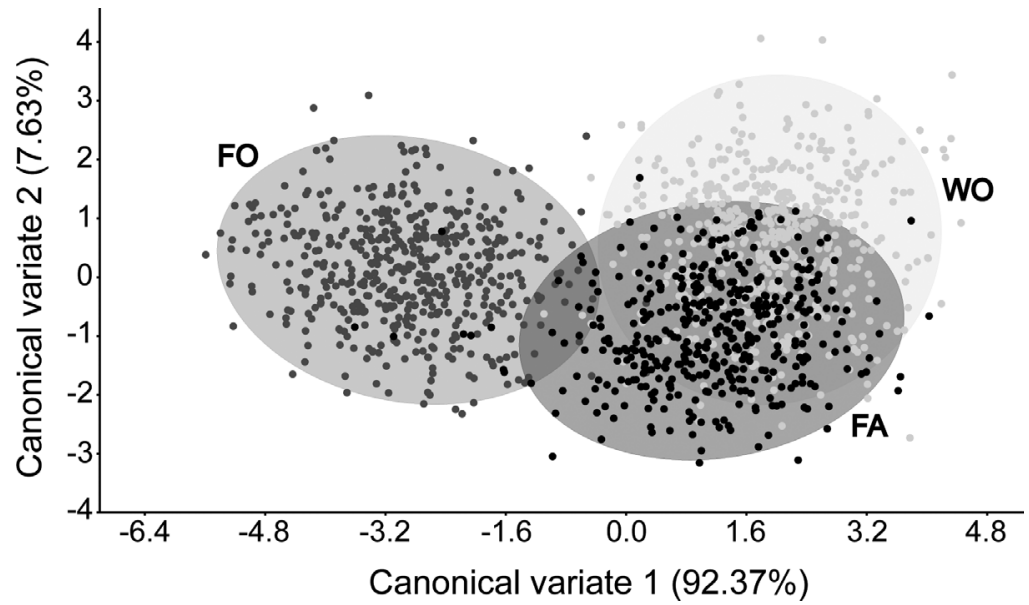

Fig. 3. Canonical variate ordination plot of sampled origins with $95 \%$ confidence ellipses of the scatter data points based on Procrustes distances. Farm-associated (FA) specimens are represented by black, farmed (FO) by dark grey and wild (WO) by light grey dots

origin, and $0.4 \%$ to WO. In FA and WO specimens, similar though higher misclassification assignments were recorded ( 22.6 and $23.92 \%$, respectively), with considerable overlap of the scatter data by $95 \%$ confidence ellipses.

By exploring shape differences at the population level, the smallest Procrustes distance value (0.0046) was recorded among FA populations $\left(\mathrm{AB}-\mathrm{AK}_{\text {; }}\right.$ see Table 1 for location definitions) and this was the only pair in the overall comparison matrix that displayed a non-significant p-value (see Table S1). Additional morphological resemblance was observed between several FA-WO populations (AK-WD, AK-WN, AB$\mathrm{WD}, \mathrm{AB}-\mathrm{WN}$ ) and among $\mathrm{WO}$ populations from the northern Adriatic (WU-WI, WI-WV). Other comparisons exhibited 1-fold higher distance values in contrast to those mentioned above (see Fig. S3, Table S1).

\subsection{LWR and biometric indices}

Regression of the transformed length-weight data of all origins showed a highly significant relationship ( $\mathrm{p}<0.0001$, Table S2), where $84 \%$ of the variation in weight $\left(\mathrm{r}^{2}\right)$ was explained for the overall sample $(n=1024)$. ANCOVA displayed a significant TL:Origin interaction term $(F=5.454, \mathrm{p}<0.01)$, resulting in different weight gain rates between specimens of different origins with increasing length (Table 3). Post hoc Tukey's test revealed significant differences when comparing WO gilthead seabream with FA $(p<0.01)$ and FO specimens $(p<0.05)$, but no LWR slope difference was recorded among FA and FO fish ( $p=$ 0.792). As a result, a second model was fitted without the interaction term and compared with the previous one to investigate the discrepancy in the intercepts (see Section 2.3 for details). The additive model was more parsimonious since the fit of the model was not significantly affected by the removal of the interaction term $(F=0.0068, \mathrm{p}=0.93)$, thereby confirming the elevation difference between regression lines where FO gilthead seabream exhibited higher values of weight at given lengths in comparison with FA individuals with a similar incremental weight gain (Fig. 4).

Monthly mean SST for the eastern Adriatic Sea in October and in November during 2 consecutive sampling years was in accordance with the climatological mean monthly SST (Pastor et al. 2018), with a temperature deviation of 1 to $2^{\circ} \mathrm{C}$ from the mean values (Figs. S4 \& S5). A MannWhitney $U$-test showed no significant difference $(U=$ 89570, $\mathrm{p}=0.224$ ) of GSI values among sampling years. Prior to ANOVA, homoscedasticity of both tested variables, i.e. Kn and GSI, were confirmed by Levene's F-test. The ANOVA revealed significant differences in $\mathrm{Kn}$ between individuals of different origins $(F=75.76, \mathrm{p}<0.01)$, and all pairwise comparisons differed significantly (Tukey's post hoc test, $\mathrm{p}<0.01$ ). Moreover, GSI also differed significantly among fish origins $(F=11.75, \mathrm{p}<0.01)$, with significant interactions of FA vs. FO and FA vs. WO (Tukey s post hoc test, $\mathrm{p}<0.01$, Fig. 5), respectively.

Table 3. ANCOVA model and Tukey post hoc tests for lengthweight relationship slope differences between farm-associated (FA), farmed (FO) and wild (WO) Adriatic gilthead seabream. TL: total length. ${ }^{*} \mathrm{p}<0.05,{ }^{* *} \mathrm{p}<0.01,{ }^{* * *} \mathrm{p}<0.001$

\begin{tabular}{|lccccc|}
\hline ANCOVA & df & Type III SS & MS & $F$ & $\operatorname{Pr}(>F)$ \\
\hline logTL & 1 & 2.523 & 2.524 & 2053.404 & $<0.000^{* * *}$ \\
Origin & 2 & 0.013 & 0.007 & 5.441 & $<0.004^{* *}$ \\
logTL:Origin & 2 & 0.013 & 0.007 & 5.454 & $<0.004^{* *}$ \\
$\begin{array}{l}\text { Residuals } \\
\text { 1018 }\end{array}$ & 1.251 & & & \\
Tukey post hoc test & & & & \\
Origin & Est. SD & SE & $z$ & $\operatorname{Pr}(>|z|)$ & \\
FO - FA & 0.083 & 0.128 & 0.650 & 0.792 & \\
WO - FA & 0.414 & 0.139 & 2.978 & $0.008^{* *}$ & \\
WO - FO & 0.331 & 0.119 & 2.760 & $0.016^{*}$ & \\
\hline
\end{tabular}




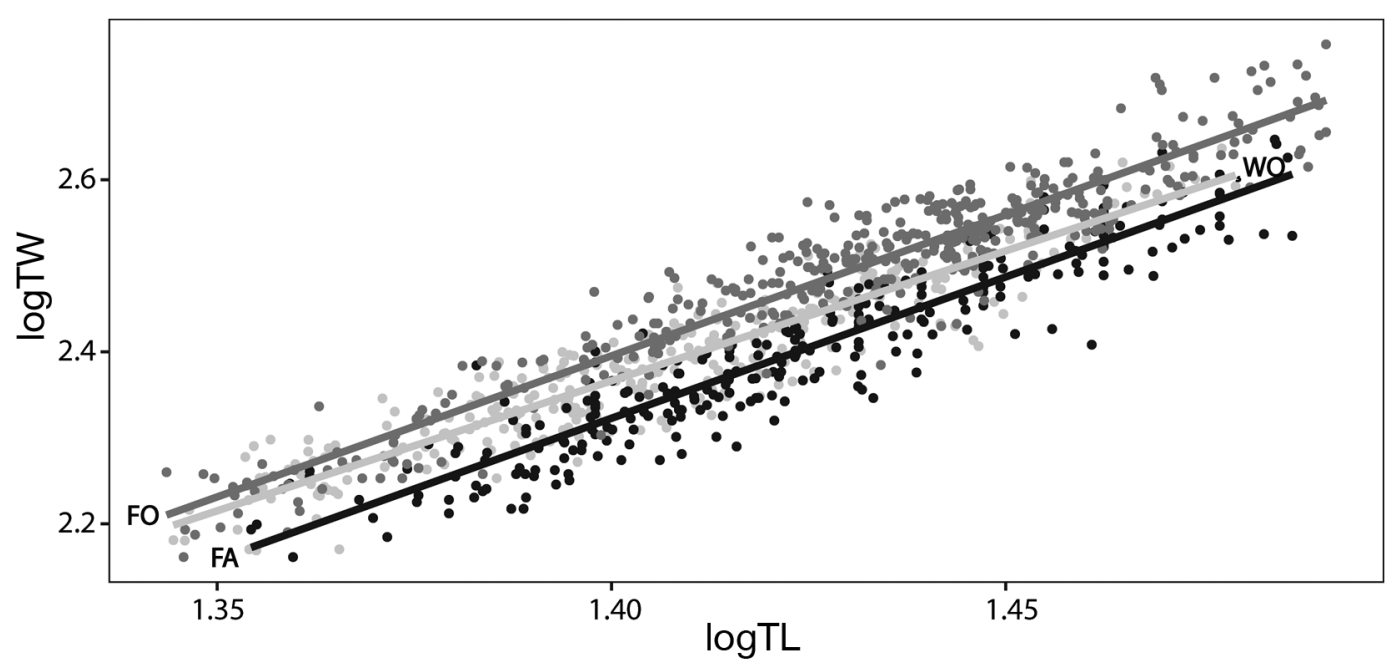

Fig. 4. Least-squares regression of $\log \mathrm{TL} \times \log \mathrm{TW}$ (where TL: total length and TW: total weight) of sampled gilthead seabream in the eastern Adriatic Sea. Farm-associated (FA) specimens are represented by black, farmed (FO) by dark grey and wild fish (WO) by light grey lines

\subsection{Sex change}

Overall, $71.3 \%$ of all specimens were male, $19.6 \%$ were in the intersex phase, and $9.04 \%$ were female (Table S3). FO populations exhibited the highest proportion of males $(97.2 \%)$, while the intersex phase $(27.4 \%)$ and female sex category $(11.9 \%)$ were most prominent in fish of FA origin. Model parameters for MLR explained a significant amount of the original variability $\left(\chi^{2}=175.2, p<0.01\right)$. The transformed test statistic and the corresponding $\mathrm{p}$-value provided sufficient evidence to conclude that the interaction term TL:Origin had an important effect on sex response categories $(0.002424 ; p<0.01)$. Sex change at given lengths depends on whether the gilthead seabream individuals were FO, FA or WO, where TL:Origin predicts whether or not individuals will undergo the change from male to female (Table 4 ). The odds ratio showed that as origin changes from WO to FA, individuals are more likely to undergo sex change with increasing length when examining parameter estimates from the male category to intersex phase $(\beta=$ 0.26 , Wald $=2.29, \mathrm{p}<0.05$, Fig. 6). No significant interaction was recorded when observing the shift from WO to FO ( $\beta=-0.06$, Wald $=-0.18 p>0.05)$, indicating that as length increases from 22 to $31 \mathrm{~cm}$, FO specimens are unlikely to undergo the change to the intersex phase. Furthermore, a significant transition from male to female was noted with increasing length when observing the change between WO to FA $(\beta=0.53$, Wald $=3.32, p<0.01)$, but with no significant interaction recorded for the change between WO and FO $(\beta=0.9$, Wald $=1.63, p>0.05$, Fig. 6$)$.

\section{DISCUSSION}

In the present study, combined morphometric and biometric analyses were conducted to investigate phenotypic plasticity of gilthead seabream in rela-

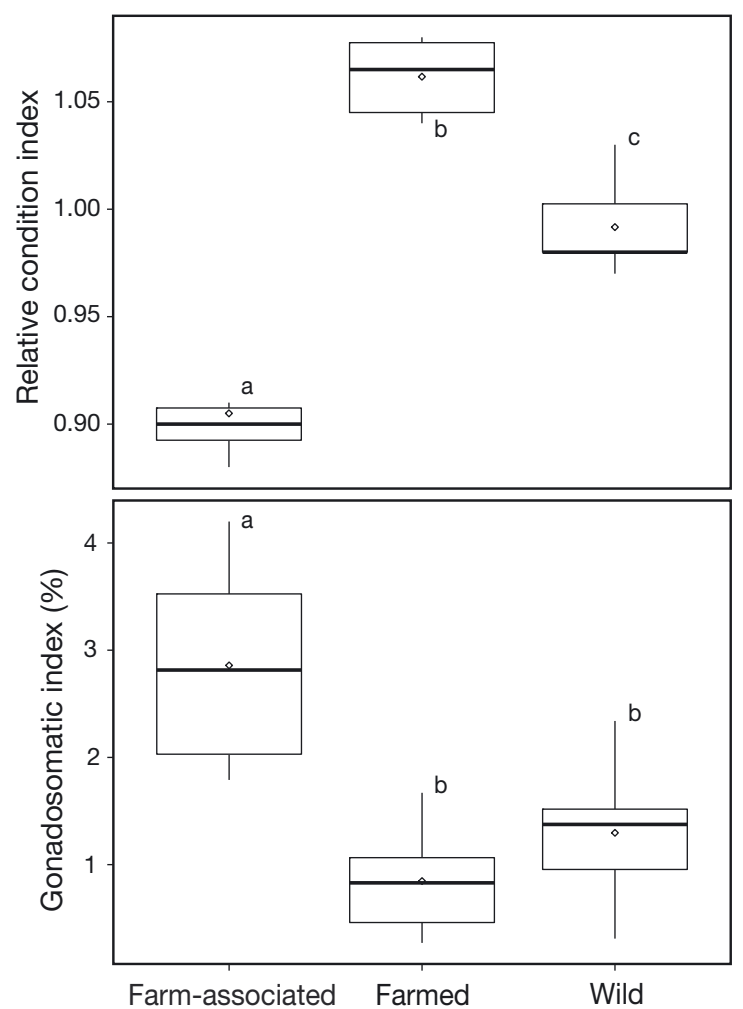

Fig. 5. Relative condition and gonadosomatic index of gilthead seabream. Same letters denote pairwise comparisons that are not statistically different 
Table 4. Results of the multinomial logistic regression of sex change analysis. $\beta$ : regression coefficient, Wald: $\beta / \mathrm{SE},{ }^{*} \mathrm{p}<0.05,{ }^{* *} \mathrm{p}<0.01,{ }^{* * *} \mathrm{p}<0.001$

\begin{tabular}{|lrrcccc|}
\hline \multicolumn{1}{|c}{$\beta$} & SE & Wald & \multicolumn{3}{c|}{$95 \%$ CI for odds ratio } \\
& & & & Lower Odds ratio Upper \\
\hline Male vs. intersex phase & & & & & \\
Intercept & -3.88 & 1.95 & $-1.99^{*}$ & & & \\
Length & 0.11 & 0.08 & 1.52 & 0.97 & 1.21 & 1.29 \\
FA & -6.97 & 3.03 & $-2.29^{*}$ & 0.00 & 0.00 & 0.36 \\
FO & -2.24 & 9.61 & -0.23 & 0.00 & 0.11 & 16.14 \\
Length $\times$ FA & 0.26 & 0.11 & $2.29^{*}$ & 1.04 & 1.30 & 1.63 \\
Length $\times$ FO & -0.06 & 0.34 & -0.18 & 0.48 & 0.94 & 1.83 \\
Male vs. Female & & & & & & \\
Intercept & -3.57 & 2.66 & -1.33 & & & \\
Length & 0.07 & 0.10 & 0.69 & 0.87 & 1.07 & 1.31 \\
FA & -14.38 & 4.31 & $-3.33^{* * *}$ & 0.00 & 0.00 & 0.00 \\
FO & -29.20 & 16.81 & -1.74 & 0.00 & 0.00 & 42.53 \\
Length $\times$ FA & 0.53 & 0.16 & $3.32^{* * *}$ & 1.25 & 1.71 & 2.34 \\
Length $\times$ FO & 0.90 & 0.55 & 1.63 & 0.83 & 2.47 & 7.31 \\
\hline
\end{tabular}

The highest level of morphological differentiation was observed in the head profile and anterior region of the fish body (see Fig. 2). CVA displayed FO gilthead seabream as fish with a stocky body form and smaller head profile with a superiorly positioned mouth, while WO individuals were distinguished by an elongated body shape and mouth positioned more subterminally on a larger head profile. FA individuals displayed a lower positioned nape and thicker belly compared to their wild counterparts and exhibited larger head profiles and a slimmer ventral body region. The inter-group classification for 3 origins showed an $84.01 \%$ correct classification score, with $2.6 \%$ misclassified assignments of FA tion to habitat use along the eastern Adriatic coast. This paper provides new insights into habitat effects on body morphology, LWR, condition, GSI and sex change of gilthead seabream originating from FA, FO and WO surroundings. For the first time, altered morphological and physiological traits were linked to semi-offshore tuna farm-impacted areas, with notably higher reproductive investment in FA populations in comparison to FO or WO populations.

The geometric morphometric analysis clearly demonstrated the divergence of FO body shape from FA and WO body form along the eastern Adriatic Sea.

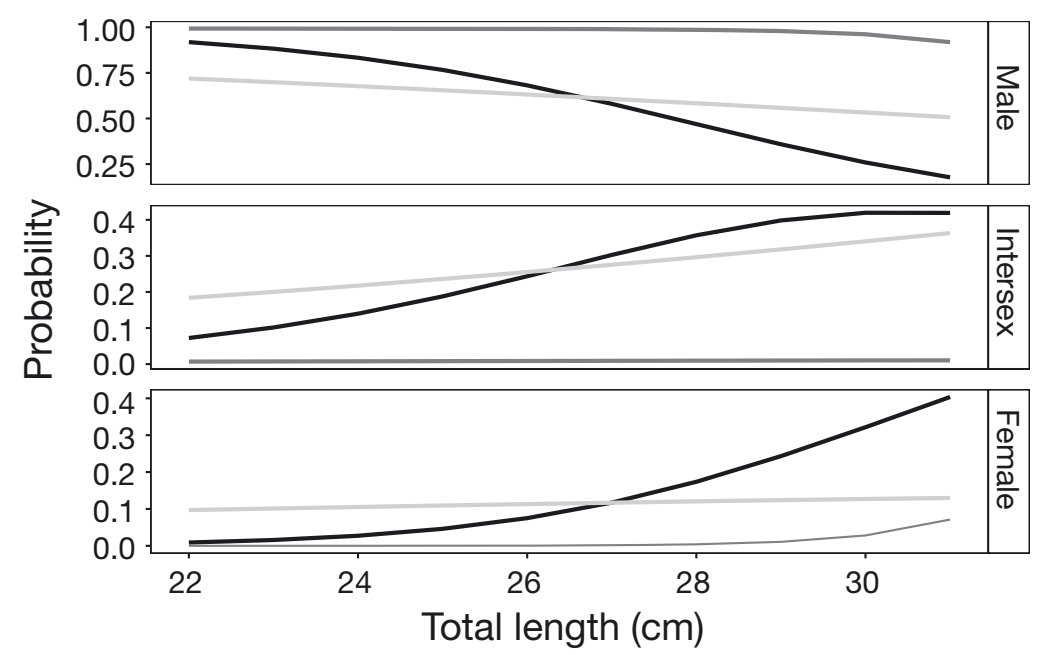

Fig. 6. Estimated multinomial regression model for sex data derived from interaction between 'Total length' and 'Origin' predictor variables. The predicted probabilities are plotted against total length of the gilthead seabream specimens by the 3 levels of origin for different categories of the sex outcome variable. Farm-associated specimens are represented by black, farmed by dark grey and wild by light grey line and $0.4 \%$ of WO individuals to FO (see Table 2). Similar findings were also reported by Šegvić-Bubić et al. (2014) in Mali Ston Bay (Croatia), where 84\% correct classification was observed for $\mathrm{FO}$ and WO individuals based on head, trunk and caudal peduncle measurements. Introgression of genes from cultured fish into the gene pool of wild counterparts and numerous reports of escape events have been reported within the eastern Adriatic (Šegvić-Bubić et al. 2011a, 2014, 2017, Glamuzina et al. 2014). Although reliable national statistics for any type of fishery landings are lacking, reports of gilthead sea bream landings have increased by $30.5 \%$ over the past 15 yr (Matić-Skoko et al. 2011). The influence of escape events on artisanal fisheries was also noted around the island of La Palma (Canary Islands), where an increment of aquaculture-based captures was reflected in the fisher association revenue in areas near the fish release point (Toledo-Guedes et al. 2014b). Studies on post-escape behaviour of farmed sea bream and seabass have shown dispersal movement patterns of escaped individuals, ranging from farm facilities to nearby farms, local fishing grounds and coastal habitats (Abecasis \& Erzini 2008, ToledoGuedes et al. 2009, Arechavala-Lopez et al. 2011, 2012b, Šegvić-Bubić et al. 2018). Therefore, the recorded misclassifications in the present study could indicate the presence of farmed gilthead seabream in wild populations, since findings along the eastern Adriatic coastline 
revealed that escapees have contributed to the mix of wild and farmed genetic stocks, an increase of local populations, enhanced artisanal fisheries and adverse effects on the shellfish industry through predation (Šegvić-Bubić et al. 2011a,b, 2014, Glamuzina et al. 2014).

Gilthead seabream in the Mediterranean display a diversity of head profiles (i.e. normal, pointed, flattened and rounded) and body shapes (i.e. stocky, bulky, discoidal, elongated, stream-like, spindle-like) in wild and farmed populations (Loy et al. 1999, Grigorakis et al. 2002, Brown 2003, Russo et al. 2007, Hurtado-Rodriguez et al. 2010, Rogdakis et al. 2011, Arechavala-Lopez et al. 2012a, Šegvić-Bubić et al. 2014, Fragkoulis et al. 2017). Our results overlap with the findings of Arechavala-Lopez et al. (2012a) where a typical elongated-spindle like body shape and larger head profile was assigned to WO fish, while the stocky body form and smaller head profile was assigned to FO fish (see Figs. 2 \& 3). Such adaptive plastic morphological responses, observed in the present fish origins, require certain environmental signals to trigger the development of the appropriate morphological feature (West-Eberhard 1989). Russo et al. (2007) revealed a significant correspondence between shape and feeding habit changes of gilthead seabream throughout its ontogeny as a result of adaptation to the availability and behaviour of different-sized prey. Rapid morphological changes were observed in the 10 to $40 \mathrm{~mm}$ size classes, primarily in the anterior region of the fish where shortening of the head and ventral positioning of the mouth was recorded, after which a stable stage was reached at $70 \mathrm{~mm}$. Considering the high plastic response of jaws and head morphology to fish diet (Wringe et al. 2015), it can be stated that the observed differences in mouth positions of FO and WO gilthead seabream (see Fig. 2) reflect different ontogenetic diet shifts. For FO fish, early implementation of inert feed in the diet and 'from the surface to the bottom' feeding technology (see Russo et al. 2007) could explain the development of a superiorly positioned mouth. Rapid morphological divergence from the wild to the farmed morphotype has been observed in the first generation of wild-caught cod offspring (Wringe et al. 2015), indicating the importance of phenotypic plasticity as a mechanism of fishes that facilitates convergence of one morphotype into the other in concurrence with the given environmental conditions. Still, those typical morpho-characteristics attributed to farmed fish are not always a reliable tool for tracing fish origin, since the production of wild-like specimens can be achieved by applying mesocosm technologies in the form of hydrodynamism, environmental diversity and constant prey availability (Boglione et al. 2001, Shields 2001).

The applied geometric morphometric methodology in the present study enables morphological identification of FA fish sampled around tuna farms with some confidence, due to the partial shape overlaps with WO fish and similar misclassification results (see Figs. $2 \& 3$, Table 2). Interestingly, the average shapes of FA populations sampled around 2 different tuna farms (AB and $\mathrm{AK}$ ) showed the highest resemblance, as opposed to other pairwise population comparisons (see Fig. 1, Table S1). It seems that the observed farms share similar environmental conditions, primarily in terms of trophic resources, which are responsible for triggering similar morphological adaptive responses in FA populations. Tuna farms are highly attractive habitats for surrounding wild fish whose aggregations of juvenile and adult stages persist year-round in large numbers, including gilthead seabreams (Šegvić-Bubić et al. 2011c, Stagličić et al. 2017). In addition to the fact that sea cages at fish farms add structure to the water column, analogous to large fish attraction devices (Dempster et al. 2011, Fernandez-Jover et al. 2011), the attraction of fish is also driven by large amounts of feed available at fish farms (Tuya et al. 2006, Fernandez-Jover et al. 2008, Sanchez-Jerez et al. 2011). Farmed bluefin tuna are fed a fat-rich diet composed of small pelagic species such as pilchard Sardina pilchardus, anchovy Engraulis encrasicolus and herring Clupea harengus (Katavić et al. 2003) to maximise body fat content for the demands of the sushi and sashimi markets (Mylonas et al. 2010). Although little is known about the estimated baitfish loss during feeding processes, losses of 4 to $23 \%$ were recorded for the southern bluefin tuna Thunnus maccoyii (Bruce 1997). This substantial portion of uneaten feed on tuna farms greatly increases feeding opportunities in the vicinity of cage infrastructures, enhancing foraging efficiency in aggregated wild fish. Furthermore, cage nets and supporting infrastructures offer thousands of square metres of surface for biofouling, upon which bivalves, the most common prey for wild seabream, constitute a large percentage of fouling communities (Fitridge et al. 2012). As opportunistic feeders, gilthead seabream will adapt their diet to the available food items in the habitat (Francescon et al. 1987, Pita et al. 2002, Arechavala-Lopez et al. 2012b), which has likely resulted in similar trophic plasticity and foraging performance between FA and WO populations residing in the vicinity of shellfish production areas (see Table S1). 
Many fish species exhibit marked morphological changes during sexual maturation cycles (Good \& Davidson 2016). Considering that the specimens in this study were sampled during the spawning period and that the chosen length range corresponds to the life stage when the majority of individuals start to consume somatic energy for various reproduction purposes (e.g. spawning, sex change), the effects of fitness indices on fish overall shape performance were noted. The highest GSI and the lowest $\mathrm{Kn}$, as indicators of energy reserve status (Lloret et al. 2014), was observed in FA fish, where enlarged ovaries occupied most of the body cavity, restricting the space for food to be ingested. This in turn broadened the trunk area in contrast to their WO counterparts, whose slender ventral body region was facilitated by a substantially lower GSI. Despite the weight increment gains being similar to those in FA fish, the stockier body shape observed in FO fish was accompanied by high Kn and low GSI. Similar observations were also noted by Grigorakis et al. (2002) and Hurtado-Rodriguez et al. (2010), where a low GSI and increased condition factor were associated with a roundish body shape due to peritoneal and perivisceral fat accumulation in farmed gilthead seabream.

A similar SST variation pattern of 1 to $2^{\circ} \mathrm{C}$ was noted for the sample period (October and November, 2015 and 2016) and the region (Figs. S2 \& S3), suggesting that the observed GSI variability among fish origins was mainly driven by the effect of tuna farming, although an effect of such small temperature variations among years and locations on gonadal development or sex change cannot be completely neglected. The higher reproductive potential of FA populations in comparison to FO and WO populations, seen through increased GSI and decreased Kn pattern in fish of FA origin, might be attributed to the fish-enriched diet in the vicinity of tuna farms. Such a diet satisfies the nutritional requirements for successful gametogenesis and viable production of eggs and larvae (Moretti et al. 1999, Izquierdo et al. 2001). It appears that FA populations have adopted the maximisation strategy of reproductive growth over energy store maximisation (Fernández-Palacios et al. 2011), which also facilitated the shape differentiation between the FA and WO fish to some extent.

The MLR for the observed length interval of 22-31 cm indicates that FA individuals are more prone to undergo sex change from male to female with increasing length compared to $\mathrm{FO}$ and WO specimens (see Table 4, Fig. 6). These results represent a deviation from the known sex change pattern of gilthead seabream, whose protandric hermaphro- dite individuals are functional males in the first $2 \mathrm{yr}_{\text {, }}$ after which they become females once they reach $\geq 30 \mathrm{~cm}$ in length (Jardas 1996, Moretti et al. 1999). The secondary sexual developmental pathway in protandric species is strongly correlated with size/age, since larger females are able to produce more eggs while smaller males are able to produce enough sperm to fertilize both smaller and larger females (Ghiselin 1969, Warner 1988, Munday et al. 2006). The size effect concept in the theory of size-dependent sex allocation for sequential hermaphrodites (Klinkhamer et al. 1997, Leonard 2013) distinguishes (1) direct benefits of size per se, such as dominance in fishes living in groups, and (2) budget effects where greater energetic resources can be devoted to gamete production or to reproduction as opposed to growth or maintenance. The observed sex change results (see Table 4, Fig. 6) indicate that the budget effect of size is present in FA populations and that the lipid content of uneaten baitfish feed might support an increasingly female-biased sex allocation as individuals increase in size. The allocation of surplus energy to male functions beyond a certain point carries little reproductive return, since females have grown to a size at which they have sufficient reproductive success even at lower length classes. Furthermore, observed increased population density of gilthead seabream in farm-impacted areas (ŠegvićBubić et al. 2011c, Stagličić et al. 2017) could also have further fostered sex change, since gender transition in hermaphrodites can occur in concert with changes in particular social/mating systems, habitat and population density (Munday et al. 2006, 2010, Avise 2011, Erisman et al. 2013). Thus, the plasticity of gonadal development and sex allocation, as a function of size/age, can be altered by the habitat and behavioural conditions in which gilthead seabream populations dwell.

In conclusion, this study provides insight into the complexity of gilthead seabream morphological and ecophysiological adaptations to different environmental settings, which could be attributed to the species reaction norms of phenotypic plasticity. In comparison to the classical or truss network measurement scheme, geometric morphometrics enabled visual interpretation of morphological discrimination between observed origin and, in conjugation with applied biometric indices, characterised components of the environment which these fish inhabited. Therefore, the establishment of databases on phenotypic and genotypic characteristics presents the next step in the effective management of cultured-wild fish interactions, and should be promoted on a larger 
regional scale in order to amend the detection sensitivity of morphological and genetic tools in future farmed-escapee identification in wild populations. Findings related to FA origin indicate that tuna farms form a unique ecological niche where wild aggregated populations have adapted their morphological and physiological states, particularly in terms of sex change and body shape. However, more research on their growth parameters, trophic structure and feeding strategies relative to reproduction are required to gain better insight into their phenotypic plasticity in comparison to their WO counterparts. This will not only contribute to the clarification of biological and ecological aspects of FA gilthead seabream, but will also help to resolve the role of tuna farms either as a population source or ecological trap for wild fish populations.

Data archive. The full dataset of farm-associated, farmed and wild gilthead seabream body shapes obtained from the eastern side of the Adriatic coast has been deposited into the GenoBase of the Institute of Oceanography and Fisheries (http://jadran.izor.hr/ tsegvic/aquapop/GenoBase.html) and is available from the corresponding author upon reasonable request.

Acknowledgements. The work of $\mathrm{PhD}$ candidate I.T. has been fully supported by the 'Young researchers' career development project - training of doctoral students' of the Croatian Science Foundation funded by the European Union from the European Social Fund under project number IP-2014-09-9050. We thank Josip Maleš and Dario Vrdoljak for their assistance in collecting sampling material.

\section{LITERATURE CITED}

Abaad M, Tuset VM, Montero D, Lombarte A, Otero-Ferrer JL, Haroun R (2016) Phenotypic plasticity in wild marine fishes associated with fish-cage aquaculture. Hydrobiologia 765:343-358

Abecasis D, Erzini K (2008) Site fidelity and movements of gilthead sea bream (Sparus aurata) in a coastal lagoon (Ria Formosa, Portugal). Estuar Coast Shelf Sci 79:758-763

Adams DC, Otarola-Castillo E (2013) Geomorph: an R package for the collection and analysis of geometric morphometric shape data. Methods Ecol Evol 4:393-399

Aguado-Giménez F, García-García B (2005) Growth, food intake and feed conversion rates in captive Atlantic bluefin tuna (Thunnus thynnus Linnaeus, 1758) under fattening conditions. Aquacult Res 36:610-614

Arabaci M, Yilmaz Y, Ceyhun SB, Erdogan O and others (2010) A review on population characteristics of gilthead seabream (Sparus aurata). J Anim Vet Adv 9:976-981

Arechavala-Lopez P, Uglem I, Fernandez-Jover D, BayleSempere JT, Sanchez-Jerez P (2011) Immediate postescape behavior of escaped seabass (Dicentrarchus labrax L.) from sea-cages in the Mediterranean. J Appl Ichthyol 27:1375-1378

Arechavala-Lopez P, Sanchez-Jerez P, Bayle-Sempere JT, Sfakianakis DG, Somarakis S (2012a) Morphological dif- ferences between wild and farmed Mediterranean fish. Hydrobiologia 679:217-231

Arechavala-Lopez P, Uglem I, Fernandez-Jover D, BayleSempere JT, Sanchez-Jerez P (2012b) Post-escape dispersion on farmed seabream (Sparus aurata L.) and recaptures by local fisheries in the Western Mediterranean Sea. Fish Res 121-122:126-135

Arechavala-Lopez P, Fernandez-Jover D, Black DK, Ladoukakis E, Bayle-Sempere JT, Sanchez-Jerez P, Dempster $\mathrm{T}$ (2013) Differentiating the wild or farmed origin of Mediterranean fish: a review of tools for sea bream and sea bass. Rev Aquacult 5:137-157

Arechavala-Lopez P, Izquierdo-Gomez D, Sanchez-Jerez P, Bayle-Sempere JT (2014) Simulating escapes of farmed sea bass from Mediterranean open sea cages: low recaptures by local fisherman. J Appl Ichthyol 30:185-188

Arechavala-Lopez P, Toledo-Guedes K, Izquierdo-Gomez D, Šegvić-Bubić T, Sanchez-Jerez P (2018a) Implications of sea bream and sea bass escapes for sustainable aquaculture management: a review of interactions, risks and consequences. Rev Fish Sci Aquacult 26:214-234

* Arechavala-Lopez P, Izquierdo-Gomez D, Forcada A, Fernandez-Jover D, Toledo-Guedes K, Valle C, SanchezJerez P (2018b) Recapturing fish escapes from coastal farms in the western Mediterranean Sea: insights for potential contingency plans. Ocean Coast Manag 151: 69-76

Avise JC (2011) Hermaphroditism. University of Columbia Press, New York, NY

Basurco B, Lovatelli A, García B (2011) Current status of Sparidae aquaculture. In: Pavlidis M, Mylonas C (eds) Sparidae: biology and aquaculture of gilthead sea bream and other species. Wiley-Blackwell, Oxford, p 1-50

Boglione C, Gagliardi F, Scardi M, Cataudella S (2001) Skeletal descriptors and quality assessment in larvae and post-larvae of wild-caught and hatchery-reared gilthead sea bream (Sparus aurata L. 1758). Aquaculture 192: $1-22$

Bookstein FL (1991) Morphometric tools for landmark data. Geometry and biology. Cambridge University Press, Cambridge

Brown RC (2003) Genetic management and selective breeding in farmed populations of gilthead seabream (Sparus aurata). PhD thesis, University of Stirling

Bruce BP (1997) A feasibility study of methods to assess and manage waste dispersal and deposition from the southern bluefin tuna (Thunnus maccoyii) farms of Boston Bay, Port Lincoln, South Australia. BSc thesis, University of Adelaide

Cadrin SX (2005) Morphometric landmarks. In: Cadrin SX, Kerr LA, Mariani S (eds) Stock identification methods: applications in fishery science. Elsevier Academic Press, San Diego, CA, p 109-124

Costa C, Cataudella S (2007) Relationship between shape and trophic ecology of selected species of sparids of the Caprolace coastal lagoon (Central Tyrrhenian sea). Environ Biol Fishes 78:115-123

* Dempster T, Fernandez-Jover D, Sanchez-Jerez P, Tuya F, Bayle-Sempere J, Boyra A, Haroun RJ (2005) Vertical variability of wild fish assemblages around sea-cage fish farms: implications for management. Mar Ecol Prog Ser 304:15-29

* Dempster T, Sanchez-Jerez P, Fernandez-Jover D, BayleSempere J, Nilsen R, Bjørn PA, Uglem I (2011) Proxy measures of fitness suggest coastal fish farms can act as population sources and not ecological traps for wild gadoid fish. PLOS ONE 6:e15646 
Dempster T, Arechavala-Lopez P, Barrett LT, Fleming IA, Sanchez-Jerez P, Uglem I (2018) Recapturing escaped fish from marine aquaculture is largely unsuccessful: alternatives to reduce the number of escapees in the wild. Rev Aquacult 10:153-167

Erisman BE, Petersen CW, Hastings PA, Warner RR (2013) Phylogenetic perspectives on the evolution of functional hermaphroditism in teleost fishes. Integr Comp Biol 53: 736-754

Fernandes M, Angove M, Sedawie T, Cheshire A (2007) Dissolved nutrient release from solid wastes of southern bluefin tuna (Thunnus maccoyii, Castelnau) aquaculture. Aquacult Res 38:388-397

Fernandez-Jover D, Sanchez-Jerez P, Bayle-Sempere JT, Valle C, Dempster T (2008) Seasonal patterns and diets of wild fish assemblages associated with Mediterranean coastal fish farms. ICES J Mar Sci 65:1153-1160

* Fernandez-Jover D, Arechavala-Lopez P, Martinez-Rubio L, Tocher DR and others (2011) Monitoring the influence of marine aquaculture on wild fish communities: benefits and limitations of fatty acid profiles. Aquacult Environ Interact 2:39-47

Fernández-Palacios H, Izquierdo M, Norberg B, Hamre K (2011) Effects of broodstock diet on eggs and larvae. In: Holt GJ (ed) Larval fish nutrition. Wiley-Blackwell, Oxford, p 153-182

Fitridge I, Dempster T, Guenther J, de Nys R (2012) The impact and control of biofouling in marine aquaculture: a review. Biofouling 28:649-669

Fleming IA, Jonsson B, Gross MR (1994) Phenotypic divergence of sea-ranched, farmed and wild salmon. Can J Fish Aquat Sci 51:2808-2824

Fragkoulis S, Christou M, Karo R, Ritas C, Tzokas C, Batargias C, Koumoundouros G (2017) Scaling of body shape quality in reared gilthead seabream Sparus aurata L. Consumer preference assessment, wild standard and variability in reared phenotype. Aquacult Res 48: $2402-2410$

Francescon A, Barbaro A, Rocca L, Bertaggia R (1987) Stima quantitativa della dieta naturale dell'orata (Sparus aurata) in ambiente salmastro. Arch Oceanogr Limnol 21:45-61

Froese R (2006) Cube law, condition factor and weightlength relationship: history, meta-analysis and recommendations. J Appl Ichthyol 22:241-253

Ghiselin MT (1969) The evolution of hermaphroditism among animals. Q Rev Biol 44:189-208

Glamuzina B, Pešić A, Joksimović A, Glamuzina L and others (2014) Observations on the increase of wild gilthead seabream, Sparus aurata abundance, in the eastern Adriatic Sea: problems and opportunities. Int Aquat Res 6:127-134

Good C, Davidson J (2016) A review of factors influencing maturation of Atlantic salmon, Salmo salar, with focus on water recirculation aquaculture system environments. J World Aquacult Soc 47:605-632

Grigorakis K, Alexis MN, Taylor KDA, Hole M (2002) Comparison of wild and cultured gilthead sea bream (Sparus aurata); composition, appearance and seasonal variations. Int J Food Sci Technol 37:477-484

Hammer Ø, Harper DAT, Ryan PD (2001) PAST: Paleontological statistics software package for education and data analysis. Palaeontol Electronica 4:1-9

Hile R (1936) Age and growth of the cisco Leucichthys artedi (Le Sueur), in the lakes of the north-eastern highlands, Wisconsin. Bull US Bur Fish 48:211-317

Hurtado-Rodriguez R, Fountoulaki E, Grigorakis K, Alexis M, Flos R (2010) Season and size effects: changes in the quality of gilthead seabream (Sparus aurata L.). Mediterr Mar Sci 11:117-131

*Izquierdo MS, Fernández-Palacios H, Tacon AGJ (2001) Effect of broodstock nutrition on reproductive performance of fish. Aquaculture 197:25-42

Jardas I (1996) Jadranska ihtiofauna. Školska knjiga, Zagreb

Katavić I, Tičina V, Franičević V (2003) Bluefin tuna (Thunnus thynnus L.) farming on the Croatian coast of the Adriatic Sea: present stage and future plans. Cah Opt Med 60:101-106

Klingenberg CP (2011) MorphoJ: an integrated software package for geometric morphometrics. Mol Ecol Resour 11:353-357

Klinkhamer PGL, de Jong TJ, Metz H (1997) Sex and size in cosexual plants. Trends Ecol Evol 12:260-265

* Koumoundouros G, Ashton C, Sfakianakis DG, Divanach P, Kentouri M, Anthwal N, Stickland NC (2009) Thermally induced phenotypic plasticity of swimming performance in European sea bass Dicentrarchus labrax juveniles. J Fish Biol 74:1309-1322

Le Cren ED (1951) The length-weight relationship and seasonal cycle in gonad weight and condition in the perch (Perca fluviatilis). J Anim Ecol 20:201-219

Leisler B, Winkler H (1985) Ecomorphology. In: Johnston R (ed) Current ornithology, Vol 2. Plenum Press, New York, NY, p 155-186

Leonard JL (2013) Williams's paradox and the role of phenotypic plasticity in sexual systems. Integr Comp Biol 53: 671-688

Lloret J, Shulman G, Malcom Love R (2014) Condition and health indicators of exploited marine fishes. WileyBlackwell, Chichester

Loizides M, Georgakopoulou E, Christou M, Illiopoulou M and others (2014) Thermally-induced phenotypic plasticity in gilthead seabream Sparus aurata L. (Perciformes, Sparidae). Aquaculture 432:383-388

Lorenzen K, Beveridge MCM, Mangel M (2012) Cultured fish: integrative biology and management of domestication and interactions with wild fish. Biol Rev Camb Philos Soc 87:639-660

Loy A, Boglione C, Cataudella S (1999) Geometric morphometrics and morpho-anatomy: a combined tool in the study of sea bream (Sparus aurata, Sparidae) shape. J Appl Ichthyol 15:104-110

*Matić-Skoko S, Stagličić N, Pallaoro A, Kraljević M, Dulčić J, Tutman P, Dragičevi B (2011) Effectiveness of conventional management of Mediterranean type artisanal fisheries. Estuar Coast Shelf Sci 91:314-324

Moretti A, Fernandez-Criado M, Cittolin G, Guidastri R (1999) Manual on hatchery production of seabass and gilthead seabream. Vol 1. FAO, Rome

Mullin SK, Taylor PJ (2002) The effects of parallax on geometric morphometrics data. Comput Biol Med 32: 455-464

Munday PL, Buston PM, Warner RR (2006) Diversity and flexibility of sex-change strategies in animals. Trends Ecol Evol 21:89-95

Munday PL, Kuwamura T, Kroon FJ (2010) Bidirectional sex change in marine fishes. In: Cole KS (ed) Reproduction and sexuality in marine fishes, patterns and processes. University of California Press, Berkeley, CA, p 214-271

Mylonas CC, De La Dándara F, Corriero A, Rios AB (2010) Atlantic bluefin tuna (Thunnus thynnus) farming and fattening in the Mediterranean Sea. Rev Fish Sci 18: 266-280

Nikolioudakis N, Koumoundouros G, Somarakis S (2014) Synchronization in allometric and morphological changes 
during metamorphosis: comparison among four sparid species. Aquat Biol 21:155-165

Olsson J, Svanback R, Eklov P (2007) Effects of resource level and habitat type on behavioral and morphological plasticity in Eurasian perch. Oecologia 152:48-56

Pastor F, Valente JA, Palau JL (2018) Sea surface temperature in the Mediterranean: trends and spatial patterns (1982-2016). Pure Appl Geophys 175:4017-4029

Pisano A, Buongiorno Nardelli B, Tronconi C, Santoleri R (2016) The new Mediterranean optimally interpolated pathfinder AVHRR SST Dataset (1982-2012). Remote Sens Environ 176:107-166

Pita C, Gamito S, Erzini K (2002) Feeding habits of the gilthead seabream (Sparus aurata) from the Ria Formosa (southern Portugal) as compared to the black seabream (Spondyliosoma cantharus) and the annular seabream (Diplodus annularis). J Appl Ichthyol 18:81-86

Policansky D (1983) Size, age and demography of metamorphosis and sexual maturation in fishes. Am Zool 23: $57-63$

Pope KL, Kruse CG (2007) Condition. In: Guy CS, Brown ML (eds) Analysis and interpretation of freshwater fisheries data. American Fisheries Society, Bethesda, MD, p 423-514

R Core Team (2013) R: a language and environment for statistical computing. R Foundation for Statistical Computing, Vienna

Rice WR (1989) Analysing tables of statistical test. Evolution 43:223-225

Rogdakis Y, Koukou KK, Ramfos A, Dimitriou E, Katselis GN (2011) Comparative morphology of wild, farmed and hatchery-released gilthead sea bream (Sparus aurata) in western Greece. Int J Fish Aquacult 3:1-9

Rohlf FJ (2001) TPS Dig 2.16 software. State University of New York at Stony Brook, NY

Russo T, Costa C, Cataudella S (2007) Correspondence between shape and feeding habit changes throughout ontogeny of gilthead sea bream Sparus aurata L, 1758. J Fish Biol 71:629-656

Safran P (1992) Theoretical analysis of the weight-length relationship in fish juveniles. Mar Biol 112:545-551

Sanchez-Jerez P, Fernandez-Jover D, Uglem I, ArechavalaLopez P and others (2011) Coastal fish farms as fish aggregation devices (FADs) In: Bortone SA, Brandini FP, Fabi G, Otake S (eds) Artificial reefs in fisheries management. CRC Press, Boca Raton, FL, p 187-208

Šegvić-Bubić T, Lepen I, Trumbić Ž, Ljubković J and others (2011a) Population genetic structure of the reared and wild gilthead seabream (Sparus aurata) in the Adriatic inferred with microsatellite loci. Aquaculture 318:309-315

‘Šegvić-Bubić T, Grubišić L, Karaman N, Tičina V, Jelavić KM, Katavić I (2011b) Damages on mussel farms potentially caused by fish predation-self-service on the ropes? Aquaculture 319:497-504

Šegvić-Bubić T, Grubišić L, Tičina V, Katavić I (2011c) Temporal and spatial variability of pelagic wild fish assemblages around Atlantic bluefin tuna Thunnus thynnus farms in the eastern Adriatic Sea. J Fish Biol 78:78-97

Šegvić-Bubić T, Talijančić I, Grubišić L, Izquierdo-Gomez D, Katavić I (2014) Morphological and molecular differenti-

Editorial responsibility: Pablo Sánchez Jerez,

Alicante, Spain ation of wild and farmed gilthead seabream Sparus aurata: implications for management. Aquacult Environ Interact 6:43-54

Šegvić-Bubić T, Grubišić L, Trumbić Ž, Stanić R, Ljubković J, Maršić -Lučić J, Katavić I (2017) Genetic characterization of wild and farmed European seabass in the Adriatic Sea: assessment of farmed escapees using a Bayesian approach. ICES J Mar Sci 74:369-378

Šegvić-Bubić T, Arechavala-Lopez P, Vučić I, Talijančić I, Grubišić L, Žužul I, Kovač Ž (2018) Site fidelity of farmed gilthead seabream Sparus aurata escapees in a coastal environment of the Adriatic Sea. Aquacult Environ Interact 10:21-34

Shields RJ (2001) Larviculture of marine finfish in Europe. Aquaculture 200:55-88

Stagličić N, Šegvić-Bubić T, Ugarković P, Talijančić I, Žužul I, Tičina V, Grubišić L (2017) Ecological role of bluefin tuna (Thunnus thynnus) fish farms for associated wild fish assemblages in Mediterranean Sea. Mar Environ Res 132:79-93

Sultan SE, Stearns SC (2005) Environmentally contingent variation: phenotypic plasticity and norms of reaction. In: Hallgrímsson B, Hall B (eds) Variation: a central concept in biology. Elsevier Academic Press, Boston, MA, p 303-332

Swain DP, Foote CJ (1999) Stocks and chameleons: the use of phenotypic variation in stock identification. Fish Res 43:113-128

Toledo-Guedes K, Sanchez-Jerez P, Gonzales-Lorenzo G, Brito Hernández A (2009) Detecting the degree of establishment of a non-indigenous species in coastal ecosystems: sea bass Dicentrarchus labrax escapes from sea cages in Canary Islands (Northeastern Central Atlantic). Hydrobiologia 623:203-212

Toledo-Guedes K, Sanchez-Jerez P, Brito A (2014a) Influence of a massive aquaculture escape event on artisanal fisheries. Fish Manag Ecol 21:113-121

*Toledo-Guedes K, Sanchez-Jerez P, Benjumea ME, Brito A (2014b) Farming-up coastal fish assemblages through a massive aquaculture escape event. Mar Environ Res 98: 86-95

* Tuya F, Sanchez-Jerez P, Dempster T, Boyra A, Haroun RJ (2006) Changes in demersal wild fish aggregations beneath a sea-cage fish farm after the cessation of farming. J Fish Biol 69:682-697

Vassallo P, Doglioli AM, Rinaldi F, Beiso I (2006) Determination of physical properties of feed pellets for Mediterranean aquaculture. Aquacult Res 37:119-126

*Vita R, Marín A, Jim nez-Brinquis B, Cesar A, Marín-Guirao L, Borredat M (2004) Aquaculture of bluefin tuna in the Mediterranean: evaluation of organic particulate wastes. Aquacult Res 35:1384-1387

Warner RR (1988) Sex change and the size-advantage model. Trends Ecol Evol 3:133-136

*West-Eberhard MJ (1989) Phenotypic plasticity and the origin of diversity. Annu Rev Ecol Syst 20:249-278

Wringe BF, Fleming IA, Purchase CF (2015) Rapid morphological divergence of cultured cod of the northwest Atlantic from their source population. Aquacult Environ Interact 7:167-177

Submitted: July 24, 2018; Accepted: December 2, 2018 Proofs received from author(s): March 4, 2019 